\title{
ЭКОНОМИЧЕСКИЕ АСПЕКТЫ КОРПОРАТИВНОЙ ИНТЕГРАЦИИ ПОДРАЗДЕЛЕНИЙ ВЫСШЕГО УЧЕБНОГО ЗАВЕДЕНИЯ В ЦЕЛЯХ ПОВЫШЕНИЯ КАЧЕСТВА ОБРАЗОВАТЕЛЬНОГО ПРОЦЕССА
}

\author{
(C) 2018 Аввакумова Ирина Владимировна \\ старший преподаватель, кафедра иностранных языков № 3 \\ Российский экономический университет им. Г.В. Плеханова \\ 115093, г. Москва, Стремянный пер., 36 \\ E-mail: imba52@mail.ru \\ () 2018 Прусакова Дарья Алексеевна \\ преподаватель, кафедра иностранных языков № 3 \\ Российский экономический университет им. Г.В. Плеханова \\ 115093, г. Москва, Стремянный пер., 36 \\ E-mail: bdgid@mail.ru \\ (c) 2018 Сидорова Елена Евгеньевна \\ старший преподаватель, кафедра иностранных языков № 3 \\ Российский экономический университет им. Г.В. Плеханова \\ 115093, г. Москва, Стремянный пер., 36 \\ E-mail: iksharik@gmail.com \\ (c) 2018 Циликова Марина Сергеевна \\ старший преподаватель, кафедра иностранных языков № 3 \\ Российский экономический университет им. Г.В. Плеханова \\ 115093, г. Москва, Стремянный пер., 36 \\ E-mail:mcilikova@mail.ru
}

В статье авторов рассмотрены экономические аспекты корпоративной интеграции подразделений высшего учебного заведения с целью повышения качества образовательного процесса. Объектом исследования выступили подразделения высших учебных заведений, а предметом - экономические аспекты их корпоративной интеграции. Теоретическое и методологическое значения исследования заключены в модернизации методической базы экономически обоснованной интеграции подразделений высшего учебного заведения, а практическое в повышении качества образовательного процесса высших учебных заведений в Российской Федерации.

Ключевые слова: экономические аспекты, экономика, корпоративная интеграция, высшие учебные заведения, подразделения, образовательный процесс, качество обучения.

В условиях конкурирования высших учебных заведений на рынке Российской Федерации за клиентскую базу абитуриентов [1, с.15] существенную значимость и актуальность приобретают вопросы повышения качества их образовательных процессов [3, с.20], которые, согласно данным последних опросов абитуриентов в Российской Федерации [6], занимают одну из ключевых позиций среди анализируемых ими показателей при выборе (рисунок 1). Данные рисунка 1 явно указывают на рост (на 24,07\% в абсолютном выражении значений анализируемого показателя или в 1,41 раз в относительном) значимости требований абитуриентов высших учебных заведений в Российской Федерации к качеству образовательного процесса за анализируемый период от 58,92\% в 2013 году до 82,99\% в 2017 году. Соответственно, важность качества образовательного процесса являлась для абитуриентов в Российской Федерации первой по величине среди прочих показателей выбора высшего учебного заведения.

Одной из тенденций последних лет, наиболее значимо проявившейся среди высших учебных заведений в Российской Федерации стала корпоративная интеграция их подразделений $[2$, 4], которая к началу 2018 года достигла уровня в $51,98 \%$. Значения уровней корпоративной инте- 


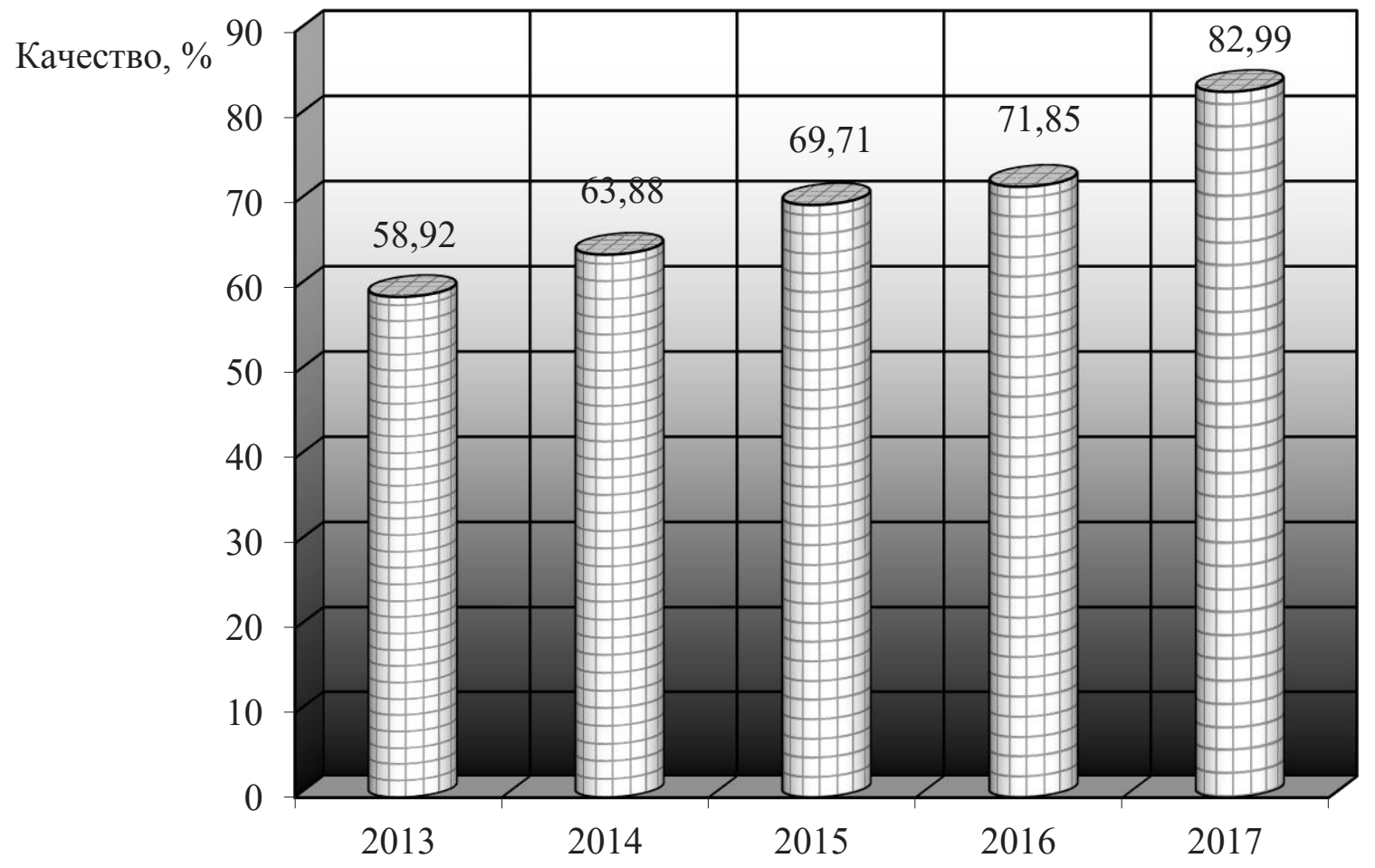

Годы

Puc. 1. Требования абитуриентов в Российской Федерации к качеству образовательного процесса в высших учебных заведениях за 2013-2017 годы (относительная значимость показателя «Качество образовательного процесса» - на рисунке 1 «Качество» в совокупности требований при выборе,\%) [6]

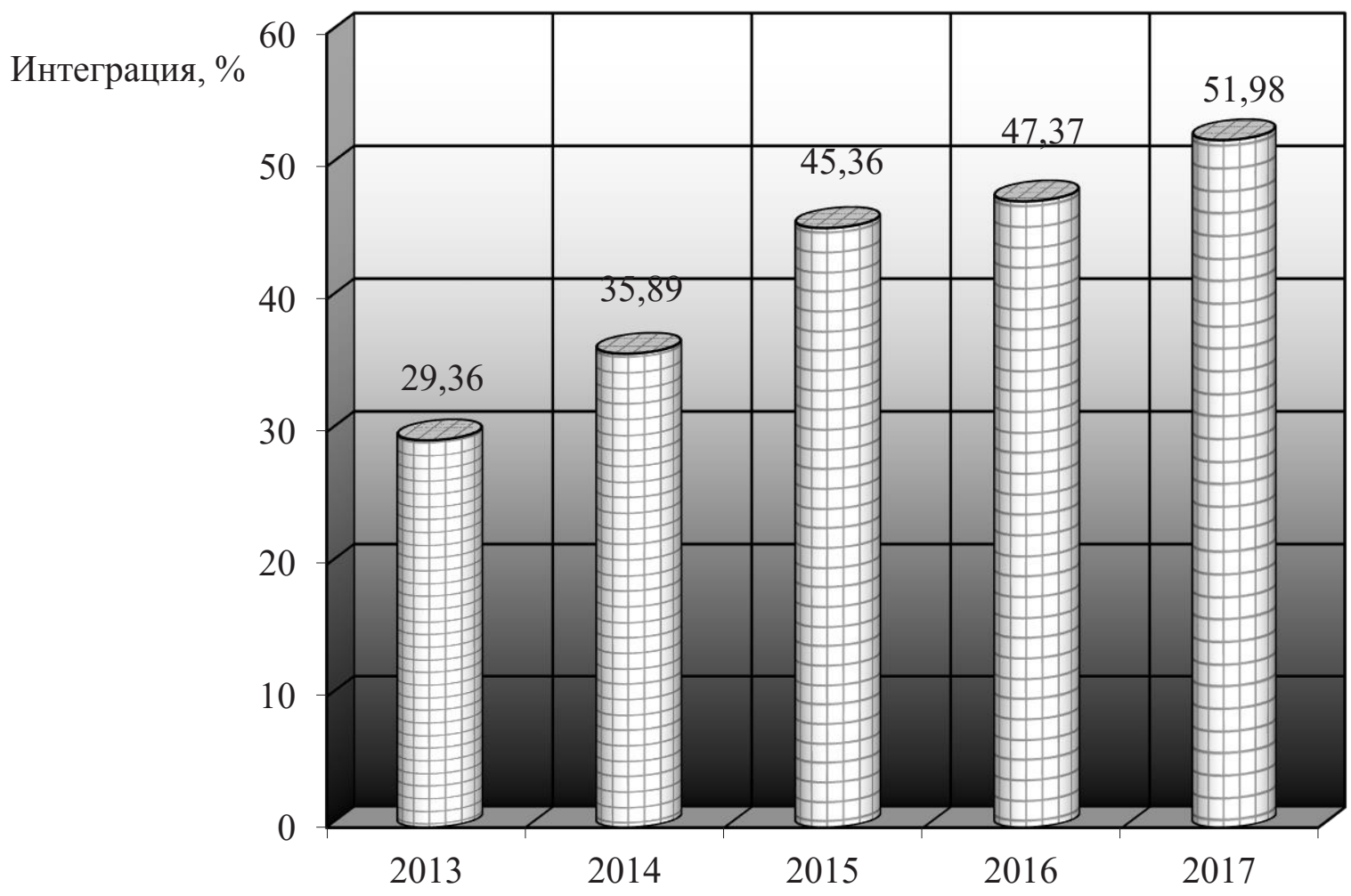

Годы

Puc. 2. Уровни корпоративной интеграции подразделений высших учебных заведений в Российской Федерации в 2013-2017 годах (усредненные данные,\%) [6] 
грации подразделений высших учебных заведений в Российской Федерации в 2013-2017 годах можно увидеть на рисунке 2. Рост уровня корпоративной интеграции подразделений высших учебных заведений за анализируемый период составил $22,62 \%$ в абсолютном выражении значений исследуемого показателя и в 1,77 раза в относительном.

Исходя из того, что уровень корпоративной интеграции подразделений высших учебных заведений в Российской Федерации в 2017 году превысил 50\%, актуальным становится вопрос оценки эффективности [5, с.57] данного процесса.

Учитывая, что более $45 \%$ высших учебных заведений в Российской Федерации [6] при разработке стратегии своего развития закладывают преимущественно показатели с экономическим содержанием (данные на начало 2018 года), далее приведем информацию по экономической эффективности процесса корпоративной интеграции подразделений высших учебных заведений в 2013-2017 годах (рисунок 3).

Примечание: показателем, формализующим выделенный ряд данных, стал коэффициент экономической эффективности корпоративной интеграции подразделений, который рассчитывается по следующей формуле:

$$
\text { КЭФКИП = }(\text { МРКИП/ЗКИП }) \times 100 \%,
$$

где:

КЭФКИП - коэффициент экономической эффективности корпоративной интеграции высшего учебного заведения за анализируемый период,\% (показатель принимает все возможные значения);

МРКИП - монетизированный результат корпоративной интеграции подразделений высшего учебного заведения за анализируемый период, тыс. руб. (показатель принимает все возможные значения);

ЗКИП - затраты на корпоративную интеграцию подразделений высшего учебного заведения за анализируемый период, тыс. руб. (показатель принимает все возможные положительные значения).

На основе данных рисунка 3 можно сделать вывод, что все проекты высших учебных заведений в Российской Федерации в сфере корпоративной интеграции в среднем имели достаточ-

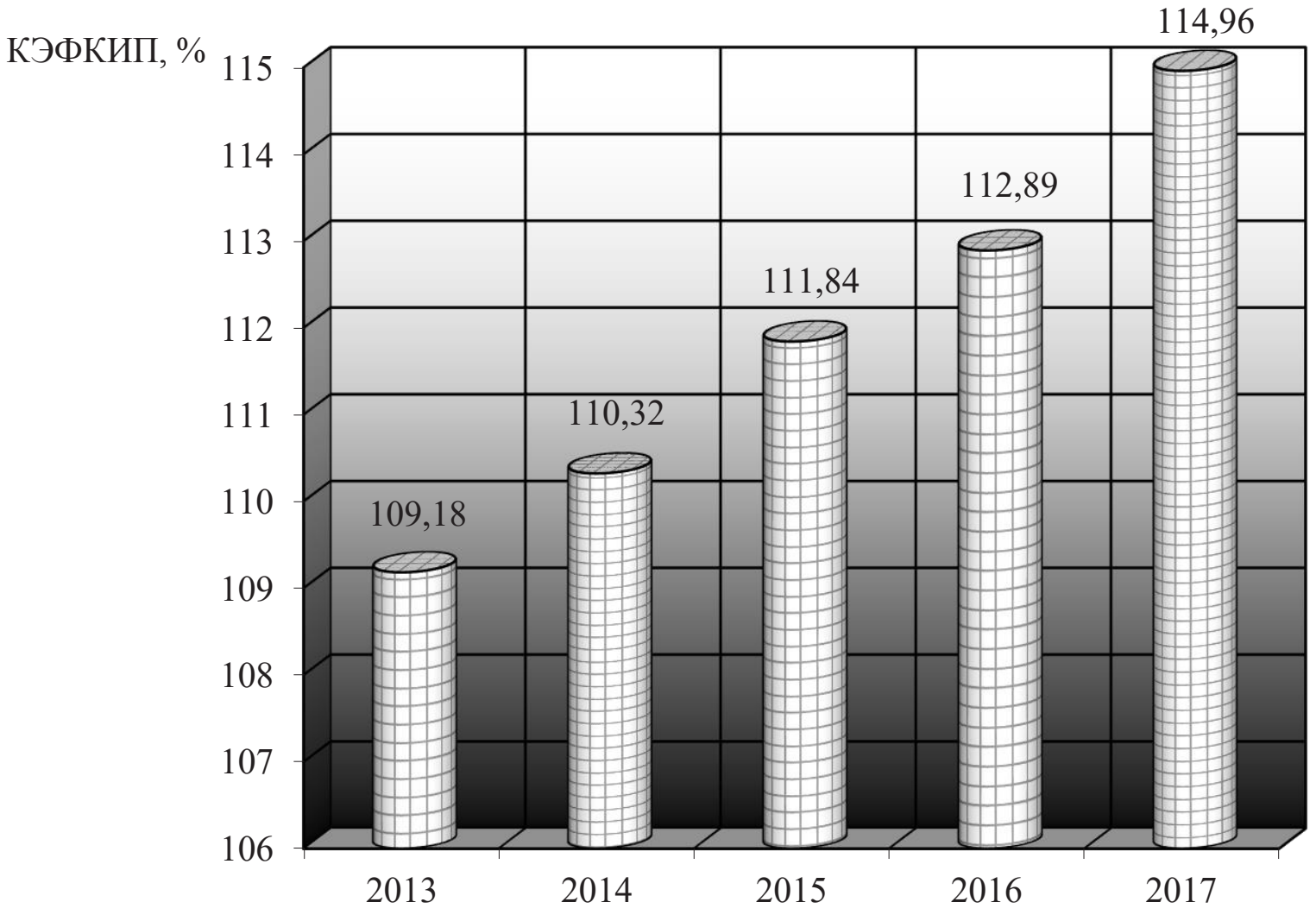

Годы

Puc. 3. Уровни экономической эффективности процесса корпоративной интеграции подразделений высших учебных заведений в 2013-2017 годах (усредненные данные,\%) 
ную экономическую эффективность, достигшую к началу 2018 года 115\% (один рубль инвестированных средств в данный вид проектов обеспечивал порядка 15 копеек чистой прибыли).

Значения показателя качества образовательного процесса (усредненные данные) в высших учебных заведениях Российской Федерации в 2013-2017 годах приведены на рисунке 4. При этом необходимо пояснить следующее:

- значение показателя измеряется в процентах;

- показатель может принимать значения от 0 процентов (минимальное значение показателя качества образовательного процесса для высшего учебного заведения) до 100 процентов (максимальное значение показателя качества образовательного процесса для высшего учебного заведения) включительно;

- расчет показателя осуществлялся по средней арифметической всех анализируемых высших учебных заведениях за анализируемый период времени.

Здесь мы можем увидеть, что качество образовательного процесса в высших учебных за- ведениях в Российской Федерации в 2013-2017 годах увеличилось в среднем на 6,27\% или в 1,09 раза. По прогнозам аналитиков в 2018 году значение исследуемого показателя в Российской Федерации возрастет до 80,35 процента (вероятность более 95,37\%), а к 2020 году сможет достигнуть $85 \%$ и более.

Коэффициенты $\mathrm{R}^{2}$ между затратами на интеграцию подразделений высших учебных заведений и динамикой коэффициентов качества образовательного процесса в Российской Федерации в 2013-2017 годах приведены на рисунке 5.

Таким образом, за весь анализируемый период связь между исследуемыми величинами носила достаточно тесный характер и не опускалась ниже значения в 0,85 единицы (2015 год). При этом максимальное значение коэффициента $\mathrm{R}^{2}$ составило 0,91 единицу (2016 год). Среднее значение анализируемого коэффициента в 2013-2017 годах находилось на уровне 0,88 единицы.

По итогам можно сделать вывод, что на рынке Российской Федерации одним из значимых

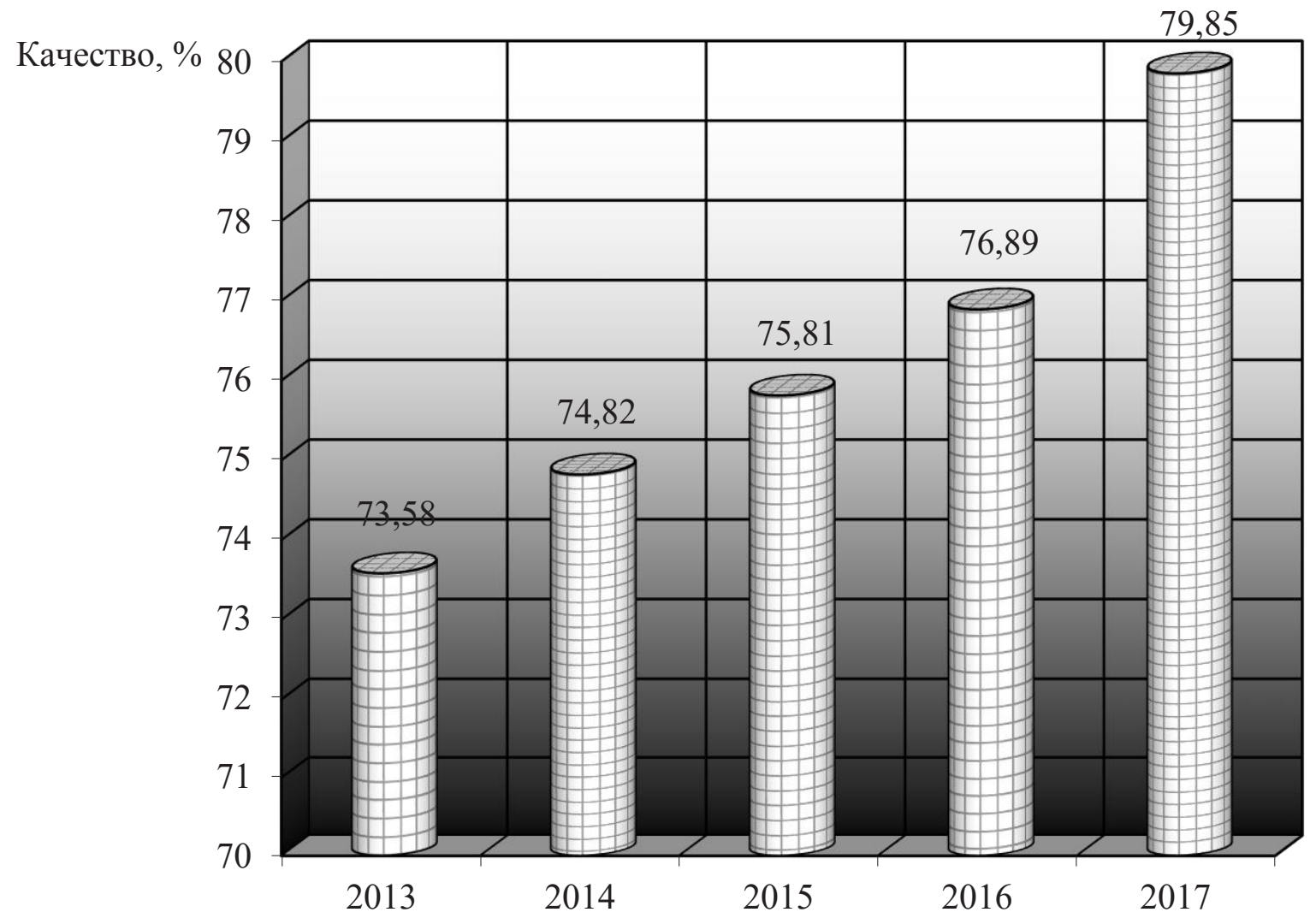

Годы

Puc. 4. Значения показателя качества образовательного процесса (усредненные данные) в высших учебных заведениях Российской Федерации в 2013-2017 годах 


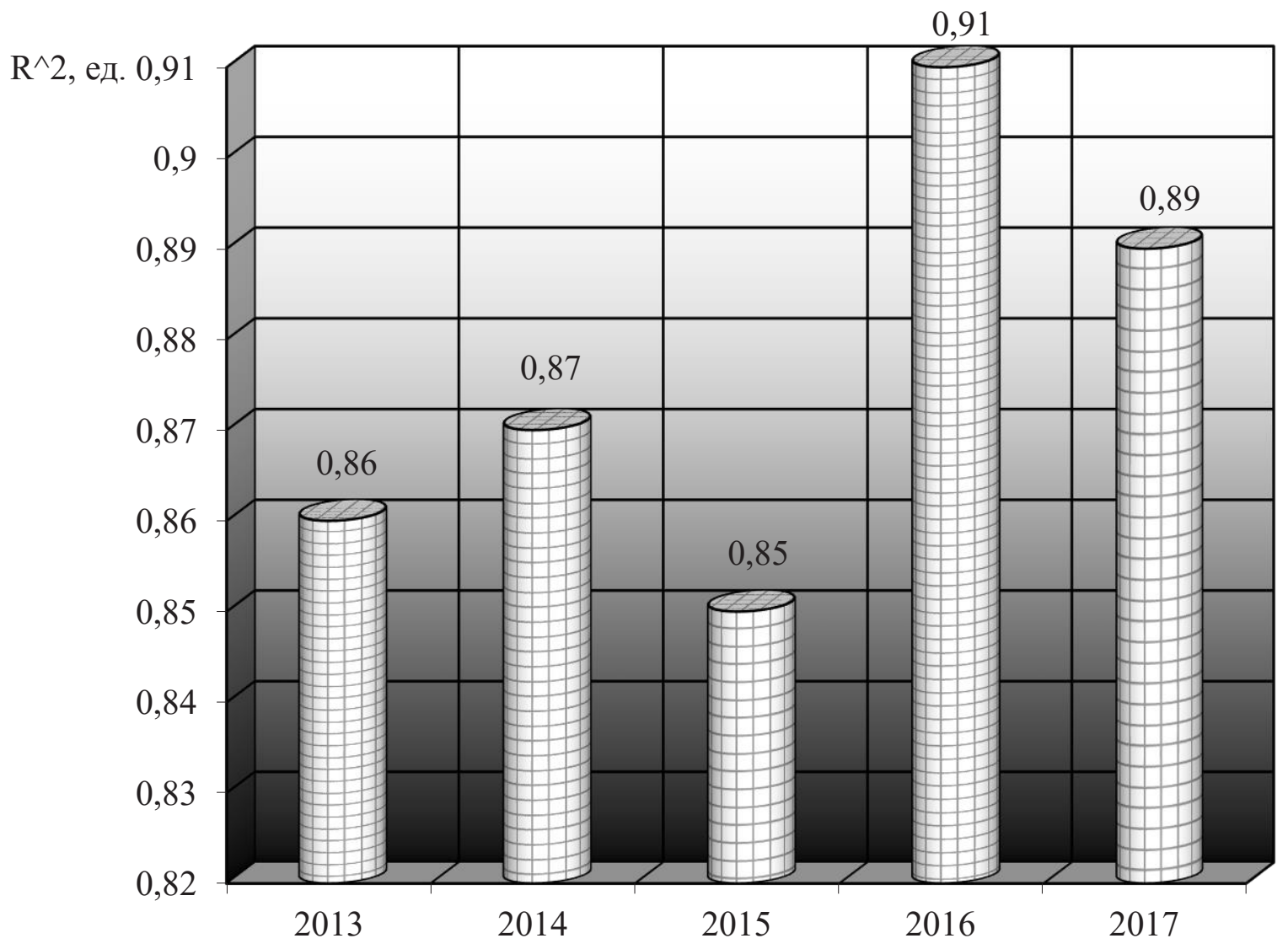

Годы

Puc. 5. Коэффициенты $\mathbf{R}^{2}$ между затратами на интеграцию подразделений высших учебных заведений и динамикой коэффициентов качества образовательного процесса в Российской Федерации в 2013-2017 годах

факторов, оказывающим воздействие на выбор абитуриентами высшего учебного заведения является качество образовательного процесса.

Для повышения уровня данного фактора и получения положительного экономического эффекта, в числе прочих мероприятий, высшим учебным заведениям в Российской Федерации целесообразно активизировать инвестирование в процессы, связанные с корпоративной интеграцией их подразделений.

\section{Библиографический список}

1. Голдобина М. В., Подборнова Е. С. Развитие качества образовательного процесса вуза // Вестник Самарского государственного университета. 2015. № 8. С. 9-16.

2. Журавлева, Ю.А. Высшее образование россиян как фактор готовности к инновационным преобразованиям: региональный аспект // Экономические науки. Москва. 2013. № 11. С.129-133.

3. Иванченко И.В. Проблема повышения качества образования в вузе // Молодой ученый. 2016. № 5.1. С. 18-21.

4. Mammen K. J. Academics' perception of 'quality in higher education', and quality strategies // South African Journal of Higher Education 2006. 20(5) P. 639-654

5. Zajda, J. Defining excellence and quality in education // New Education. 1994. 16(2). P. 53-61.

6. [Аналитические материалы // Вопросы образования. 2018. Электронный ресурс - Режим доступа: http:// vo.hse.ru/ 